the former being encouraged to undertake approved investigations in aeronautics for which they are fitted. It is proposed to create a chair and department of aeronautics (probably in the University of Sydney) to ensure a supply of trained personnel for military and civil aviation and for aeronautical construction. A readership in meteorology will also be established.

The Research Committee will form sub-committees to deal with aerodynamics ; power plant ; navigation and meteorology; materials ; accidents ; and air inventions. It will also be required to investigate the use of Australian-produced materials and processes in aircraft construction; and it will maintain a general information service.

On the automobile side it is proposed to set up an Industrial Research Committee to assist the Council with advice on a programme of research and to seek the co-operation of the industry in making provision for the carrying out of it.

It will be some considerable time before the projected laboratory is completed, but a start will be made in the current financial year. Provision is being sought for $£ 143,000$ to cover capital expenditure, and the estimated annual maintenance cost is put at $£ 12,000$.

\title{
Electrical Interference with Radio Reception
}

$\mathrm{I}^{\mathrm{T}}$ has been well known for some years that a large proportion of electrical apparatus and plant, of both a commercial and domestic character, produces discontinuous electrical currents, which can result in interference with radio reception over a wide range of frequencies. In view of the widespread use of broadcast receivers in everyday life, it is very much in the public interest that all possible steps should be taken to mitigate the results of such interference. In NATURE of August 1, 1936, reference was made to the work of a joint committee representative of all sections of the electrical and radio industries in the study of this problem. Following the report of this committee, a number of other committees have been at work under the auspices of the British Standards Institution compiling specifications of components which may be fitted to electrical apparatus and to radio receivers with the object of reducing the nuisance of interference to a minimum. Concurrently with the operation of these committees, the Post Office on one hand and the British Electrical and Allied Industries Research Association on the other, have been carrying out investigations on a comprehensive scale.

The results of such investigations were summarized at a meeting of the Wireless Section of the Institution of Electrical Engineers on April 6, when a paper was read by Mr. A. J. Gill (of the Post Office) and Dr. S. Whitehead (of the Electrical Research Association) under the title "Electrical Interference with Radio Reception". The paper described the method of assessment of the interference to radio reception by electrical equipment, and the degree to which such interference must be reduced to permit satisfactory service. Various methods of measuring the interference have been developed in different countries and the most reliable of these have been compared with the view of securing uniformity of interpretation of the results.

With the aid of such apparatus, a study has been made of the interference produced under typically practical conditions from such electrical sources as trolley-buses, high-voltage overhead power lines, highfrequency medical apparatus and surgical equipment, electric lifts, telegraph and telephone plant, domestic appliances and the ignition systems of motor-cars. It has been found that while in some cases the interference is experienced by direct radiation from the source, it is more common for the interfering voltages to set up currents in the electrical supply network, from which the mains at the receiving station radiate locally to the receiving aerial. Following this appreciation of the nature and magnitude of the source of the interference, a detailed study has been made of methods of suppression to the level required to give satisfactory reception. Where possible, it is naturally best to suppress the interference at its source; but where this is either impracticable or unduly expensive, it is necessary to take steps to improve conditions at the receiver itself. Very effective methods of suppression have been worked out in some detail and some typical results of applying these are described in the paper. It is by the continued friendly co-operation between the electrical and radio industries that continued progress is to be anticipated as the methods of suppression and mitigation now available come into widespread use.

One of the methods adopted by the Post Office in dealing with this matter has been by co-operation with the ordinary broadcast listener in investigating complaints of interference brought to the notice of this Department. The number of such complaints brought to the attention of the Post Office has increased from some 10,000 in 1931 to nearly 50,000 in 1937. To deal with this problem, a full-time staff of about 250 are employed, and these have been trained by special courses of instruction. The equipment available to this staff comprises 110 motor-vans, each supplied with an interference locator, portable wireless receiving set, screened leads and a number of suppression components for demonstration purposes. The work of this staff has already produced a great amelioration in the conditions of broadcast reception. It is interesting to note that in some cases the broadcast listener is himself the cause of much of the interference of which he complains; for although it may not be usual in any one household to listen to broadcast programmes at the same time as the vacuum cleaner or electrically driven sewing machine is in use, these items may cause considerable interference to neighbouring listeners. Perhaps the time is not far distant when the man in the street may insist that all new domestic electrical appliances which he purchases will have been certified as 'interference free'.

The paper, to which reference was made above, concludes with an extensive bibliography, which indicates the large amount of scientific and technical work which has been devoted to this subject. 